Dir. 762

NBSIR 79-1949 (Navy) $R$

\title{
Evaluation of Selected Navy Equipment for the Women-Aboard-Ship Program
}

Robert L. Paila, úr.

Clarke E. Jones

C. Denver Lovett

Louis G. Forter

Center for Consumer Product Technology

and

Eelinda L. Coilins

Center for Builóing Technology

National Engineering Laboratory

National Bureau of Standards

Washington, D.C. 20234

December 1979

Issued January 1980

Prepared ior

U.S. Department of the Navy Naval Ship Engisseering Ceriter

Washington. D.C. 20362 



\section{EVALUATION OF SELECTED NAVY EQUIPMENT FOR THE WOMEN-ABOARD-SHIP PROGRAM}

Robert L. Palla, Jr.

Clarke E. Jones

C. Denver Lovett

Louis G. Porter

Center for Consumer Product Technology

and

Belinda L. Collins.

Center for Building Technology

National Engineering Laboratory

National Bureau of Standards

Washington, D.C. 20234

December 1979

Issued January 1980

Prepared for

U.S. Department of the Navy

Naval Ship Engineering Center

Washington, D.C. 20362

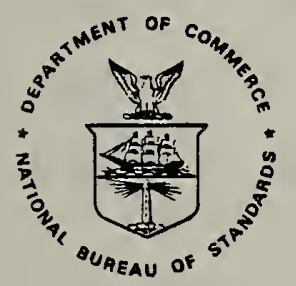

U.S. DEPARTMENT OF COMMERCE, Philip M. Klutznick, Secretary

Luther H. Hodges, Jr., Deputy Secretary

Jordan J. Baruch, Assistant Secretary for Science and Technology

NATIONAL BUREAU OF STANDARDS, Emest Ambler, Director 



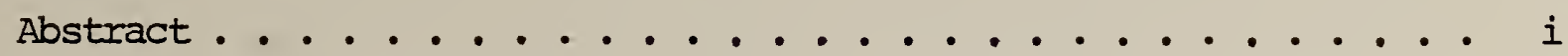

1.0 Introduction ................. I

2.0 Anthropometric/Biomechanical Differences Between Males and

Females ................ 2

3.0 An Ergonomic Evaluation of the Selected Equipment . . . . . 7

3.1 Oxygen Breathing Apparatus (OBA) . . . . . . . . 8

3.1.1 Fit of OBA ................ 9

3.1 .2 Bulk and Weight of $\mathrm{OBA}$......... 10

3.1 .3 OBA--as a Unit ................ 10

3.2 Safety Harness . . . . . . . . . . . . 10

3.2.1 Fit of Safety Harness . . . . . . . . . . 10

3.2.2 Operation of Energy Absorber Device . . . . . 12

3.3 Escape Scuttle ................. 13

3.4 Life Rails and Life Lines .............. 14

3.5 Rotary Observation Windows ............ 15

4.0 summary and Conclusion .................. 15

5.0 References .................... 18

Table 1. Anthropometric and Biomechanical Dimensions for Males and Females ................... 3

Table 2. Specifications and Relevant Anthropometric Data for

Selected Equipment ............. 4

Table 3. Example of Iscmetric Force Exerted Over Time . . . . . 7

Table 4. Possible Problem Areas . . . . . . . . . . . 7

Table 5. Hazard Categories for Navy Equipment . . . . . . . . 8

Table 6. Hazard Classifications for the Selected Equipment . . . 16

Table 7. Problem Identification/Evaluation . . . . . . . . 17

Figure 1. Range and Mean Percentage Differences in Muscle Strength

Characteristics Between Women and Men ....... 6

Appendix A. Anthropometric and Biomechanical Data Capabilities . . 19

Appendix B. Anthropometric and Biomechanical Dimensions of Male

and Female Populations .......... 25 

A study of the human factors aspects of five selected items of Navy equipment, namely, oxygen breathing apparatus, safety harmess, emergency escape scuttle, life rails, and rotary observation windows, has been undertaken to ensure that the smaller size and lesser strength of females would not be a deterrent to the use of the equipment by women. The study involved a review of the applicable specifications for each item of equipment, a survey and enumeration of male and female anthropometric data, and a linking of engineering and anthropometric data. Each item has been assigned to a hazard category.

Of the five items evaluated, two appear to pose significant problems when used by women. Fit and high deceleration forces were the major concerns for the safety harness while operating force requirements were critical for the escape scuttle. In addition, there were also some difficulties for some women in the use of the oxygen breathing apparatus. 

In the Fall of 1978 , the U.S. Navy began the task of assigning women to sea-duty on non-combatant ships other than hospital or transport ships. While the presence of women on Navy ships is not expected to alter normal operations, there are design features of ships and shipboard equipment which may require modification for use by females. The most obvious, of course, involve considerations of sleeping quarters, and similar ship features. In addition, though, equipment and systems may require modification if they are to be used extensively by women.

Most naval shipboard safety and emergency escape equipment currently in use was designed for the 5 th to 95 th percentile male with respect to height, weight, and physical strength. Approximateiy 25 percent of the female population is sinaller, lighter, and weaker than the 5 th percentile male. In view of these differences, the adequacy of critical equipment should be reassessed as during an emergency, survival could depend upon the ability of women to operate the equipment successfully.

The Naval Ship Engineering Center (NAVSEC) was given the task of assessing the impact upon systems and equipment if the crews of non-combatant ships were staffed from 20 to 50 percent by women. NAVSEC identified an initial group of five items of equipment which might not perform adequately when operated by females. These items included: oxygen breathing apparatus (OBA)--type A4, safety harness, enlergency escape scuttles, life rails and lifelines, and rotary observation windows. A study of the human factors aspects of this equipment was then undertaken to ensure that no serious problems would arise through female use. This study involved--

- direct observation of the equipment use aboard ship;

- review of applicable engineering specifications and blueprints for each item of equipment;

- survey and enumeration of both male and female anthropometric data; and

- linking of engineering and anthropometric data. 
The goal of this investigation was the identification of any potential safety or performance problems. Results of the study are presented in this report.

\subsection{ANTHROPOMETRIC/BIOMECHANICAL DIFEERENCES}

BETWEEN MALES AND FEMALES

Two of the major areas of difference between present day male crewmembers and female crewmembers are body dimensions (anthrcpometry) and body action (biomechanics). Body dimensions are critical to sizing of personal equipment, operating equipment, access and mobility space and work space. Body action is critical to all of these requirements and, in addition, to force application in a wide variety of tasks and general activities. Therefore, the gap between the lower percentile female anthropometric and biomechanical dimensions and the dimensions of the 5 th percentile male crewmembers is a critical research area for adaptation of women crewmembers to an environment designed for a male crew. Details of current anthropometric/biomechanical data capabilities are presented in Appendix A. References to selected works which deal with the subject are also included.

Presented in Table 1 are some comparative anthropometric data on selected dimensions from male and female populations. These represent the best approximations available for those populations from which male and female Navy crewmembers may be obtained. The dimensions given were primarily selected as body configuration and strength characteristics which could be considered as descriptors of male and female similarities and differences which might be encountered in decisions regarding utilization of female crewmembers aboard Navy ships. The procedure used in selecting this data is explained in detail in Appendix $B$. Additional anthroponetric data, relevant to each of the selected pieces of equipment, is presented in Table 2 .

The usual caveat for this kind of data applies where the population from which the data are obtained may not be representative of Navy male and female crewmembers. Also, the data are descriptive of people, not task performance requirements. It is to be expected that the data will be 


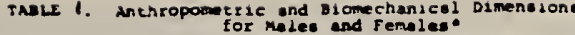

\begin{tabular}{|c|c|c|c|c|c|c|}
\hline Dinentzone & Populetson & sets $1120=$ & $\operatorname{soch} 111$ & 9sen 1110 & Overlapes & Romarke \\
\hline wesoht $\left(R_{\pi}\right)$ & U.s. Axtry P & 46.63 & s9.58 & 74.52 & 52 & $\begin{array}{l}\text { A11 body mensurements are } \\
\text { in brs and pant } 2 \text { cs or under }\end{array}$ \\
\hline Insd & U.5. Army n & 57.35 & 70.95 & 91.65 & & $\begin{array}{l}\text { ahort and bare foot, unies } \\
\text { otherwize atated. }\end{array}$ \\
\hline Steture (C) & v.s. Army $P$ & 152.0 & 162.7 & 174.1 & 3: & Floor to top of head \\
\hline Inid & U.3. Axing $n$ & 263.7 & $17+.4$ & 135.4 & & \\
\hline Sirting Eajght (a) & D.s. Arm ? & 79.01 & $\begin{array}{l}83.17 \\
90.75\end{array}$ & $\begin{array}{l}90.32 \\
96.68\end{array}$ & 37 & $\begin{array}{l}\text { Sitting surface to top } \\
\text { of head }\end{array}$ \\
\hline $\begin{array}{l}\text { Sbid } \\
\text { Bust Depth (a) }\end{array}$ & D.s. Arme & 29.60 & 22.74 & 26.81 & & Tip of bre to back of \\
\hline Chest Depen (ns) & v.s. Axmy $n$ & 20.19 & 23.02 & 26.70 & 95 & 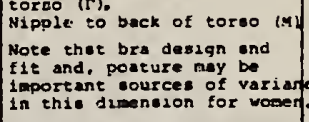 \\
\hline Shoulder Bresdeh (an) & u.s. Amy ? & 39.41 & .2 .01 & 45.66 & 4) & $\begin{array}{l}\text { Maximum breadth across } \\
\text { nhoulder at bulges of }\end{array}$ \\
\hline Ibid & J.s. Arry & 41.46 & 45.23 & 49.77 & 9 & $\begin{array}{l}\text { deltoid muaclea in upper } \\
\text { arm }\end{array}$ \\
\hline Eis Breadth (Ca) & U.s. Arsy ? & 32.33 & 35.25 & 39.54 & 63 & $\begin{array}{l}\max 2 m u m \\
\text { of horizontel bleaden }\end{array}$ \\
\hline Ibid & U.s. Army $x$ & 30.16 & 33.05 & 36.72 & 63 & \\
\hline waist nolght (a) & U.s. Aimy $P$ & 93.21 & 101.10 & 110.31 & 64 & $\begin{array}{l}\text { Plooz to notursl velot } \\
\text { level (F). }\end{array}$ \\
\hline Ibld & U.S. Asm & $97 .+6$ & 106.35 & 115.16 & & 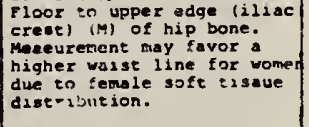 \\
\hline His rircurerence (ca) & "I.s. Asmy ? & 85.89 & 99.28 & 106.1 & & \\
\hline Ibid & O.s. Anty $\mathrm{n}$ & 85.12 & 93.58 & 105.5 & & \\
\hline Upper migh C1reunfermee (a) & U.S. Army $>$ & 49.35 & 56.20 & 64.52 & & \\
\hline Ibid & O.3. Nay $x$ & 40.07 & 35.10 & 63.86 & & \\
\hline $\begin{array}{l}\text { Waist Pront lengeh (Ca) } \\
\text { (oot availsble for male } \\
\text { pooulation) }\end{array}$ & $\begin{array}{l}\text { D.s. Axwy F } \\
\text { v.s. Axwy }\end{array}$ & $\begin{array}{l}32.78 \\
-110\end{array}$ & $\begin{array}{l}36.52 \\
A V \times I I\end{array}$ & $\begin{array}{c}41.36 \\
A 82 \\
\end{array}$ & $\cdots$ & $\begin{array}{l}\text { Surface difference fron } \\
\text { waststo antersor (front) } \\
\text { rieck-torso junction. }\end{array}$ \\
\hline Vertical srunk Circunference io & D).s. Aray $P$ & 142.2 & 155.5 & 166.1 & s1 & $\begin{array}{l}\text { Tape phssing through the } \\
\text { croech, Ever the buttock } \\
\text { and shoulder, and the tip }\end{array}$ \\
\hline Ibid & U.s. Anny $x$ & 150.6 & 163. 3 & 178.6 & & 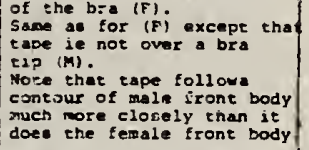 \\
\hline $\begin{array}{l}\text { Waret anck Longth (en) } \\
\text { lbid }\end{array}$ & $\begin{array}{l}\text { 0.5. Aney P } \\
\text { 0.5. Arng } \%\end{array}$ & $\begin{array}{l}36.71 \\
39.52\end{array}$ & 40.73 & $\begin{array}{l}45.49 \\
50.83\end{array}$ & 49 & $\begin{array}{l}\text { Surface diatance froa } \\
\text { cervical pcint to walse }\end{array}$ \\
\hline send Lengeh (a) & 0.5. ADP & 16.06 & 17.30 & 19.04 & 39 & Wriet creese to tip of \\
\hline Ibsd & U.s. AnE & 17.51 & 19.00 & 20.66 & 39 & \\
\hline Band Circwaferencer(ca) & D.s. Aray? & 17.05 & 18.43 & 29.87 & $2 \mathrm{i}$ & $\begin{array}{l}\text { Around metecarpal - pha lan- } \\
\text { geat jo2nte (knuekles and }\end{array}$ \\
\hline ibid & 0.5. גasty & 19.83 & 21.56 & 23.56 & & exclualing thumb). \\
\hline $\begin{array}{l}\text { Fand areaden (cal) } \\
\text { Ib1d }\end{array}$ & 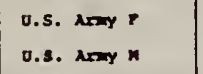 & 9.10 & 7.82 & $\begin{array}{l}9.46 \\
9.74\end{array}$ & 22 & $\begin{array}{l}\text { Acroak paim at dintal and } \\
\text { metecarpal bonee (knuekle } \\
\text { level). }\end{array}$ \\
\hline $\begin{array}{l}\text { rumertanel Raech (CD) } \\
\text { Ibid }\end{array}$ & $\begin{array}{l}\text { D.s. Axyy P } \\
\text { D.s. Axw A }\end{array}$ & $\begin{array}{l}64.02 \\
74.90\end{array}$ & $\begin{array}{l}71.08 \\
22.45\end{array}$ & $\begin{array}{l}76.99 \\
90.92\end{array}$ & 22 & 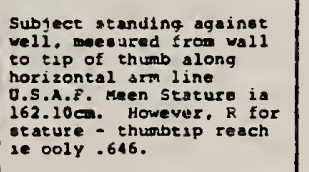 \\
\hline $\begin{array}{l}\text { Standing Vortical Grip } \\
\text { Reech (a) }\end{array}$ & $\begin{array}{l}\text { Righ sehnol } P \\
117.5-19.0 \text { yra.. }\end{array}$ & 188.4 & 196.4 & 205.6 & & Floor to \\
\hline Ibid & $\begin{array}{l}\text { Bigh School } 7 \\
(17.5-19.0 \text { yтu. })\end{array}$ & 206.0 & 213.8 & 228.9 & $\begin{array}{l}\text { (baaed on mis rung } \\
\text { and maximum) }\end{array}$ & 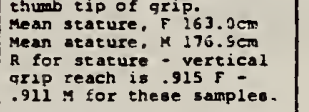 \\
\hline Beot rorso Jesghe (0) & U.s. Asmy P & 112.7 & $13 x .7$ & $: 25.5$ & Iasufficient ia & $\begin{array}{l}\text { Floor to top of heed in } \\
\text { atooped pouition (E,M). }\end{array}$ \\
\hline Ibid & U.S.A.P. M & 127.6 & $1: 2.1$ & 150.0 & & $F$ clothed, 9 may be cluthe \\
\hline $\begin{array}{l}\text { Rreoling Heigbt - Upriogt (an) } \\
\text { Inid }\end{array}$ & $\begin{array}{l}\text { D.s. Anty P } \\
\text { U.S.A.t. A }\end{array}$ & $\begin{array}{l}114.5 \\
122.4\end{array}$ & $\begin{array}{l}122.92 \\
129.54\end{array}$ & 130.3 & Iosufticient Data & $\begin{array}{l}\text { Floor to top of head, on } \\
\text { knees witn torso erect. } \\
\text { F clothed, M may be clothe }\end{array}$ \\
\hline $\begin{array}{l}\text { Grip strength }(n) \\
\text { Ibid }\end{array}$ & $\begin{array}{l}\text { college, } \\
\text { college, }\end{array}$ & $\begin{array}{l}197 \\
352\end{array}$ & 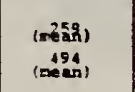 & $\begin{array}{l}320 \\
636\end{array}$ & Ineuffieient Data & $\begin{array}{l}\text { Smedley hand dynamometer, } \\
1 \mathrm{~N}(\text { ewton })=0.224 \mathrm{~s} \text { laf }\end{array}$ \\
\hline $\begin{array}{l}\operatorname{Max} 1 \mathrm{mum} \text { Acceptable weight } \\
\text { Lift. (kg) } \\
\text { Ibld }\end{array}$ & Indus. Morkers. & $\left(\begin{array}{lll}10 \\
13 \\
10 \mathrm{ch} & 110\end{array}\right.$ & 15 & $\mid \begin{array}{l}(90 \text { th atile) } \\
21 \\
(90 \text { tratile) } \\
29\end{array}$ & Insufficient io & $\begin{array}{l}\text { Wo hand repetitive lift } \\
\text { of tote box } 34.3 \times 48.3 \times \\
\text { 14.0 cm loaded with lead } \\
\text { snot, floor to knuckle } \\
\text { hej ght }\end{array}$ \\
\hline $\begin{array}{l}\text { Maximus reasonable veight. } \\
\text { carry }(\mathrm{kg}) \\
\text { Ibid }\end{array}$ & $\left\{\begin{array}{l}30-44 \text { yrs. } P \\
30-44 \text { yra. }\end{array}\right.$ & $\begin{array}{r}9.57 \\
11.60\end{array}$ & $\begin{array}{l}16.00 \\
21.50\end{array}$ & $\begin{array}{l}22.13 \\
31.40\end{array}$ & Insufficient & $\begin{array}{l}\text { Tro hand carry of box } \\
\text { loaded by subject to an } \\
\text { icceptable weight for the } \\
\text { subject }\end{array}$ \\
\hline $\begin{array}{l}\text { Forvard Puen, both hande (s) } \\
\text { Ibic }\end{array}$ & $\begin{array}{l}\text { colloge, } F \\
\text { college, } M\end{array}$ & $\begin{array}{l}118 \\
281\end{array}$ & 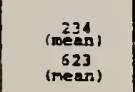 & $\begin{array}{l}343 \\
366\end{array}$ & Ineufficient ta & $\begin{array}{l}\text { Reaction forge Frovided by } \\
\text { floor and fDor res: } \\
1: \text { i (evton })=3.2248 \text { 10f }\end{array}$ \\
\hline \multicolumn{7}{|c|}{ 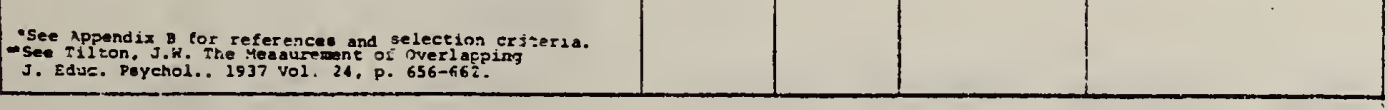 } \\
\hline
\end{tabular}




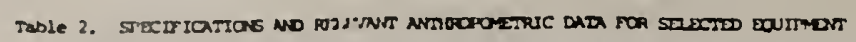

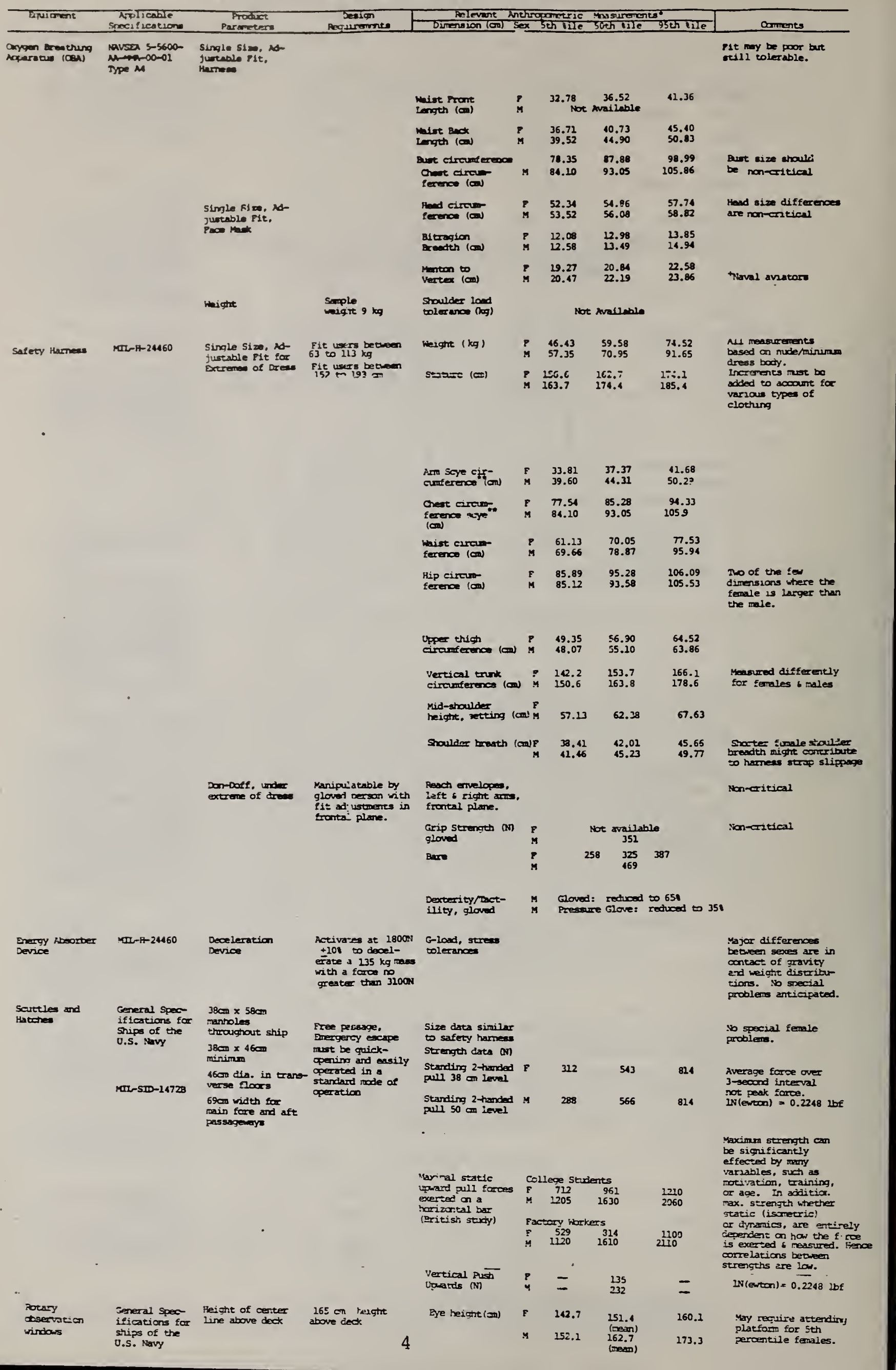


pertinent to a wide range of operational requirements onboard ship but many tasks will probably call for physical configurations and capabilities not mentioned herein. Finally, some dimensions are not exactly equivalent for both men and women even though they may involve the same body or performance areas. Chest measurements are an obvious example.

Comparison of body measurements between the sexes (Table I) reveals the obvious. The male is generally larger than the female, although there is a considerable amount of overlap. In only two dimensions, namely hip breadth and circumference and thigh circumference. are females consistertly larger than the male. By interpolating between anthropometric data, it is noted that for most dinensions approximately 20 to 25 percent of all females have measurements falling outside the range of measurements for the 5 th through the 95 th percentile male. Examination of the head measurement data of Table 2 indicates that there are only very small differences between the male and the female, with the female face being somewhat smaller. However, these small variations in facial size and shape may be critical in achieving a good facemask fit.

Studies comparing the strengths of males and females indicate that the female's strength is from 50 to 80 percent that of the male, depending on the strength measured (see Figure 1) [1]. Under normal conditions, most task requirements are well below the maximum strength potentials of both male and female, so that sex differences are not critical. However, some stress conditions of long-term duration may produce performance degradations to the point where maximum strength potentials are below task requirements. This relationship is best illustrated by considering the case of force exertion over time. As shown by fictitious example in Table 3 , although the performance decrement from one minute to one hour is proportionally the same (50\%) for both sexes, a female's performance after one hour would be unacceptable for tasks requiring forces greater than 26 newtons. Therefore, a task that can just be sustained for one hour by a male would obviously have to be terminated in less than one hour by a female. 


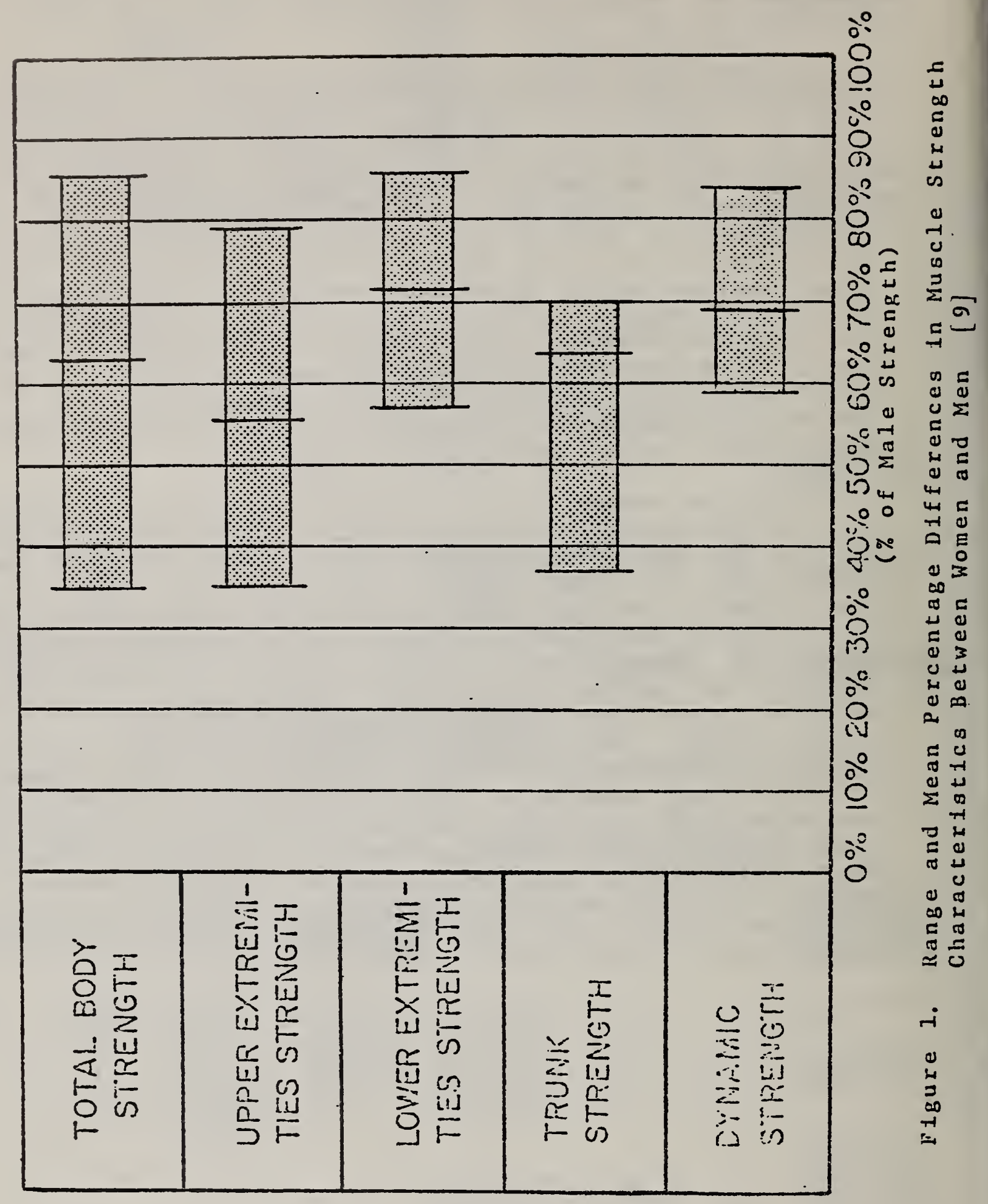


Table 3. Example of Isometric Force Exerted Over Tine Sustained for $1 \mathrm{Min}$ Sustained for $1 \mathrm{Hr}$

$\begin{array}{lll}\text { Men } & 80 \mathrm{~N} & 40 \mathrm{~N} \\ \text { Women } & 52 \mathrm{~N} & 26 \mathrm{~N}\end{array}$

Unfortunately there is a scarcity of dynamic strength data for females. This type of information is currently being developed by Robertson [2].

\subsection{AN ERGONOMIC EVALUATION OF THE SELECTED EQUIPMENT}

Based on a visual inspection and a review of specifications and operating characteristios of the selected equipment, possible problem areas were identified. These areas, presented in Table 4, were later considered in greater depth in order to determine whetiner anthropometric/oiomechanical differences between males and females might cause significant problems for female persornel or ship safety.

Table 4. Possible Problem Areas

\section{Equipment}

Oxygen Breathing Apparatus

Safety Harness

Escape Scuttle

Life Rails, Stanchicns, Life Lines

Rotary Observation Window

\section{Possible Problem Area}

Fit of breast plate, face piece Weight and bulk of apparatus

Fit

Operation of Energy Absorber Device

Physical Capabilities (strength required to operate)

Differences in bulk, weight, and weight distribution of personnel

Distance from floor to windows Viewing area

While it is recogrized that problems in these areas may also be experienced by male personnel, the equipment was analyzed in terms of "special" problems which might affect females more severely, particularly those 20 to 25 percent females 
having physical characeristics falling outside the range of the 5 th through 95 th percentile male.

Four hazard categories, presented in Table 5, were developed as criteria for evaluating the performance of safety items. These criteria were applied in the evaluation of the five pieces of equipment for use by females.

Table 5. Hazard Categories for Navy Equipment

Category 非--items that will pose a serious threat to personnel safety, impair mission performance, or cause damage to essential equipment or systems.

Category 非--items that are likely to result in a deterioration in successful performance or a marked increase in personnel siress. The level of performance degradation under this category is not intolerable, but does represent a compronise of effectiveness and efficiency over a measurable span of time.

Category 非3--items that do not perform satisfactorily when used as intended, but which can be modified by the user to perform adequately. These devices have characteristics which permit the user to adapt them, adjust them, or use a supplementary device for successful operation. The penalty for such modification may be excessive stress or fatigue for the user. The items could permit proper use and satisfactory performance with slight design modification.

Category 非--items that present no apparent consequence as a result of operation by female users.

In the remainder of this section, the significance of each aforementioned possible problem area is assessed for the selected equipment. The equipment is then categorized using the preceding criteria.

\subsection{Oxygen Breathing Apparatus (OBA)}

Problems with the OBA, which might be experienced by female users, include 1) poor fit and 2) reduced freedom of movement and fatigue/poor performance due to the bulk and 
weight of the apparatus. While these problems also exist for male personnel they may tend to affect female performance more severely.

\section{1 .1 Fit of $C B A$}

Body harness/breastplate: The OBA body harness is adjustable and allows the OBA to be worn high or low, and tight or loose on the chest. As such, the OBA should accommodate virtually all female personnel. Unfortunately, in some cases, the fit obtained will be less than acceptable--particularly, for smaller, lighter females. The shorter trunk length of these personnel can result in OBA interference with the facepiece or the upper front thighs while bending: climbing or changinê oxygen canisters, and should therefore be of concern.

The problem of OBA fit becomes apparent upon consideration of the relevant anthropometric data and OBA dimensions. Anthropometric data presented in Table 2 indicates that the waist front length for females ranges from abcut 33 to $41 \mathrm{~cm}$. Comparable data for males is not available, but measurements presented in Table 2 indicate that the waist back lergth for males is about 3 to $5 . \mathrm{cm}$ greater than for females. Waist front lengths for males might similarly be 3 to $5 \mathrm{~cm}$ greater than for females or about 38 to $46 \mathrm{~cm}$. In contrast to waist front length, the length of the OBA when worn is about $43 \mathrm{~cm}$. Comparison of waist front and $O B A$ lengths indicates an overlap of as much as 10 cm--between the upper legs and the OBA, and the OBA and the shoulders--for female users, versus an overlap of 5 $\mathrm{cm}$ for male users. The effects of this aditional $5 \mathrm{~cm}$ overlap for fenales on body movement and job performance are not expected to be significant but should be further investigated.

Face Piece: The OBA face piece headband straps are adjustable and do not appear to present any problem with female use. Face piece sealing, however, may rot be satisfactory with some female facial contours.

Naval Air Systems Command has found that some woren aviators require a face mask with a laminar seal (Type $A B A$ ) in order to achieve complete sealing [3].

Discussions with Mine Safety Appliances Co. (MSA) [4], manufacturer of the OBA, indicate that a similar sealing problem with the OBA face piece is possible in 
some cases, but the problem is not of immediate concern.

\section{1 .2 Bulk and Weight of $O B A$}

The weight of the OBA is approximately $9 \mathrm{~kg}$ ( 20 $1 \mathrm{bm})$. A search of the literature failed to yield data relevant to the weight of equipment worn by individuals. However. female back-packers normally carry 20 to $30 \mathrm{~kg}$ in a back-pack configuration. Since the OBA is worn in front the OBA's weight per se should not be critical to female performance. In conjunction with a poorly fitting body harness, however, the net effect could have a significant impact on female performance--such as passing through a scuttle or fighting a fire for an extended period of time.

\section{1 .3 OBA--as a Unit}

Due to size and strength differences, females may experience performance decrements below an acceptable level during OBA use. The OBA should therefore be considered as a Category 非 problem. The rationale for placing the whole OBA unit in Category 2 is that the interaction of weight, interference, other accouterments, and hostile environment may result in performance below some tolerable level. On the other hand, the male having the same performance decrements may still perform above the same toleraile level.

\subsection{Safety Harness}

The safety harness under consideration is of the parachute harness type. It is adjustable to provide it over outer garments and other accouterments such as a life jacket. Possible problems which may result with female use of the device include poor harness fit and faulty operation of the accompanying energy absorber device.

\subsubsection{Fit of Safety Harness}

The harness requires a good fit around the upper thighs and hips, which are intended to absorb most of the deceleration energy. Less critical are the shoulder straps which distribute the deceleration energy over the chest; however, the possible distribution of the 
As specified in MIL-H-24460, the safety harness shall fit users between 63 and $113 \mathrm{~kg}$ ( 140 and $250 \mathrm{lbm}$ ) in weight and between 152 and $193 \mathrm{~cm}$ ( $5 \mathrm{ft}$ and $6 \mathrm{ft} 4$ in) in height. Inspection of Table 2 indicates that a harness meeting this specification might fail to fit half of all female personnel because their weight falls outside the specified range.

A sample safety harness was test fitted on two females. These persons represented low and high percentile weight and medium to high percentile height for female populations. Poor fit--due to excessive shoulder strap length--was obtained in both cases, i.e. the shoulder strap could not be tightened enough to give a snug fit. A shorter shoulder-to-waist distance for females was identified as a factor contributing to this poor fit. Apparently, the combination of shorter waist front and waist back lengths for some females (see section 3.1.1) results in a required strap length shorter than attainable by adjusting the harness.

Since women participate in sky-diving, parachute jumping, and other aerial acrobatics, the question arose as to whether female's parachute harresses are different from the males. Information from the National Parachute Test Range at El Centro, California, indicated that size (weight and height) was (somewhat) more important than sex. Apparently, in order to accommodate the wide range of height and weight of personnel, the Air Force uses 12 harness sizes [5]. An additional safety harness size might also be required tc accommodate females in the Navy program.

Another concern with the safety harness involves shoulder straps slipping off the shoulder. This could present a safety problem if the straps were riding the periphery of the shoulders at the time of a fall. Two factors would tend to increase shoulder strap slippage for females: 1) the shoulder straps might fit on the outside edge of the bosom and 2) female shoulder breadth is about $3 \mathrm{~cm}$ smaller than males.

Modification of existing safety harnesses to reduce shoulder strap slippage might involve the addition of a snap-on crosspiece between the two chest straps to reduce the possibility of straps slipping of $f$ 
shoulders. Addition of the crosspiece would increase the safety of male users as well as female users.

Safety harness redesign efforts, if required. should consider 1) including such a crosspiece and 2)

increasing the range of shoulder and waist strap

adjustment to compensate for small framed personnel and

personnel with greater waist to shoulder measurements.

\subsubsection{Operation of Energy Absorber Device}

The requirement for the energy absorbing device is that it activates at $1800 \mathrm{~N}+10 \%(400 \mathrm{lbf}+10 \%)$. Also, it should decelerate a $13 \overline{5} \mathrm{~kg}$ ( $3001 \mathrm{bm}$ ) mass with a force no greater than $3100 \mathrm{~N}(700 \mathrm{lbf})$, without producing an elongation of more than $61 \mathrm{~cm}$ ( $2 \mathrm{ft}$ ). A $135 \mathrm{~kg}$ simulated human torso is used in a.free-fall drop-test to check that the device meets specifications. It should be noted that this test is not sufficient for evaluating the effect of deceleration on personnel safety since it checks force levels and not g-loadings.

It is possible that a light female, under some fall conditions, would fail to activate the energy absorbing device because of low forces, yet still be subjected to high enough g-loadings to cause serious injuries. A full explanation of the rationale for 8 load testing to simulate lightweight personnel (63 kg ( $140 \mathrm{lbm})$ or less) is rather lengthy; the reader is referred to "A Study of Personal Fall-Safety

Equipment." [6] It is strongly recommended that the energy absorbing device be investigated further to insure that lightweight personnel would not be subjected to intolerable g-loadings. Satisfactory operation can be insured by testing the absorber with a light mass as well as the presently used heavier mass.

Because of questions regarding safety harness fit, shoulder strap slippage, and energy absorber operation, the safety harness appears to pose significant safety problems for female users. Until more definitive data, and perhaps results of actual use tests are obtained, the safety harness should be considered a Category 1 item. 


\subsection{Escape Scuttle}

Several different size scuttles are currently being used on Navy'ships. These range in size from $46 \mathrm{~cm}$ ( 18 in) diameter scuttles used on older ships, to $64 \mathrm{~cm}$ (25 in) diameter spring-balanced units. Most common are $53 \mathrm{~cm}$ (2l in) diameter scuttles, which are used on new ships. These $53 \mathrm{~cm}$ units, designed so that the maximum upward force required for operation does not exceed $220 \mathrm{~N}$ (5C Iij), appear to pose the most significant problems with regard to operation by females.

The major problem with escape scuttles appears to be the force required to operate them. Two processes are involved in scuttle operation: turning a wheel to unlock the scuttle, and forcibly lifting or pushing the scuttle open. Of concern here is whether females. generally weaker than males, would be physically capable of performing these tasks.

Locking/Unlocking Scuttles: The force required to lock and unlock escape scuttles is generally dependent on (I) the degree of tightening either required for sealing or previously used respectively, (2) dirt/corrosion buildup on locking mechanism components, and (3) scuttle alignment/sealing problems. Although force requirements for locking/unlocking are not specified as scuttle design requirements, maintenance procedures aimed at assuring satisfactory scuttle operation are specified. However, the force requirements for scuttle operation can still be excessive in some cases, and beyond the physical capabilities of some males as well as females.

In order to adequately assess problems pertaining to scuttle operation, an analysis or survey of operating force requirements should first be undertaken. Once the range of forces required to open the scuttle has been established for scuttles, then it should be verified that female recruits can meet these requirements. This requires measur ement of the strength, torque, and force needed for scuttle operation, as well as verification that females can meet these requirements.

Lifting/Pushing Scuttles Open: In evaluating problems with female use of scuttles, the two different modes of scuttle operation must be considered--operation from above deck involving lifting strength, and operation from below deck involving pushing strength. 
Comparison of upward pull strength data presented in Table 2, with scuttle lifting force requirements ( $220 \mathrm{~N})$ suggests that when scuttles are activated from above, the force requirements appear to be within the capacity of the 5 th percentile female. However, actuating access/exit openings from below may prove to be an especial problem for females. As shown in Figure 1, for example, the static strength in the upper extremities of women was found to be roughly 55 percent that of men while for the lower extremities it was found to be about 72 percent of that of men. Women's trunk strength was found to be 64 percent of that of men [1]. These findings indicate that the female is at a more severe disadvantage vis-a-vis the male when she is required to use arm/shoulder muscles--especially if the arms must be used above the head. What limited vertical upward push data exists ( see Table 2) indicates that average fenale strength, $135 \mathrm{~N}$, is significantly less than that required to push th $53 \mathrm{~cm}$ scuttle $(220 \mathrm{~N})$ open. Male strength, $232 \mathrm{~N}$. is only barely sufficient. These figures, while appearing to be low, indicate that the scuttle is indeed more of a problem for females than for males.

In summary, when actuated from above deck, scuttles do not appear to present any special problems for female personnel. However, when operated from below, females might lack the upper body strength required to open the scuttle. For this reason, the scuttle is considered a Category 1 problem.

In addition to the problem of force requirements for scuttle operation, there appears to be potential safety related problems due to inadequate footholds and lighting in the scuttle shaft. The addition of an extra foothold on the opposite side of the ladder would allow a person to support both feet, and thus increase stability while trying to open the scuttle. Use of lighted, fluorescent, or raised markings on the scuttle might also increase ease of operation. An examination of relevant Navy accident records should bear out any real problems.

\section{4 Life Rails and Life Lines}

Inspection of human factors data presented in Table 1 indicates that women are only slightly smaller than men in body width and depth measurements. Also, a female's center of mass would tend to be at a lower vertical elevation than a male's due to shorter female height and greater weight concentration at midbody level. These factors combined 
would tend to reduce the likelihood of females falling between or over life rails, perhaps making this even less of a problem than for males. As Iife rails and life lines do not present significantly greater danger for women than that currently experienced by men, these items are considered to fall into Category 4.

\subsection{Rotary Observation Windows}

The primary visual problems that might arise for the Women-Aboard-Ship program are mainly related to differences in female height. One such problem involves the use of rotary observation windows by short personnel.

The specifications for rotary observation windows require that the center line of the window be $1.64 \mathrm{~m}$ above deck. At this height. the lower edge of a typical $33 \mathrm{~cm}$ diameter spinning window would be about $1.47 \mathrm{~m}$ above the deck. Examination of the eye height data of Table 2 reveals that roughly one-fourth of all females will require a stool or other stable and sturdy platform to bring their eye level with the window's center line. Because the range of male heights is so great, wooden platforms and stools have already been provided on the bridges of many ships to overcome this problem as it relates to windows. These same devices should compensate for male-female height differences in most cases and additional platforms can be provided for shorter females. Because the eye height problem is easily solved using techniques presently in use, windows and other such devices would appear to be noncritical for the WomenAboard-Ship program. They are therefore considered to be Category 3 items. A consideration of greater ranges in height should be made when positioning apertures in new ship design.

\subsection{SUMMARY AND CONCLUSIOI}

Five selected iterns of Navy equipment have been evaluated with regard to operation by female personnel, particularly, those females with physical attributes falling outside the range of the 5 th through 95 th percentile males. These items were categorized in terms of the hazards they may present to ship and personnel safety when operated by female personnel. A summary of the hazard classifications for the selected equipment is presented in Table 6. 
Table 6. Hazard Classifications for the Selected Equipment

\section{Equipment}

Oxygen Breathing Apparatus (OBA)

Safety Harness

Escape Scuttles

Life Rails and Life Lines

Rotary Observation Windows
$1 \quad \frac{\text { Category Number }}{2}$

$\mathrm{X}$
$\mathrm{X}$

$\mathrm{X}$

Of the five items evaluated, two are considered to pose significant personnel or ship safety problems related to female operation; these are the safety harness and the emergency escape scuttle. With the safety harness, problems with fit, shoulder strap slippage, and high deceleration forces for lighter personnel appear likely. For the scuttle, the force required to open it froin below is expected to be greater than the upper body (arm) strength of many females (the strength in the upper extremities of females is about 55 percent that of males). Accordingly, both pieces of equipment are classified as Category 1 items.

Use of the oxygen breathing apparatus (OBA) by female personnel is also of concern as interaction of possible problems cited in this study--OBA weight, poor face piece/OBA fit, and fatigue--may result in unacceptable performance. Hence, the OBA is considered a Category 2 i tem.

Performance of two remaining items--life rails and life lines, and rotary observation windows--appears to be sex neutral. No female related problems with life rails and life lines have been identified, and eye height associated problems (for short personnel) with rotary windows are easily solved by adding platforms to stand on. These devices are therefore considered Category 4 and Category 3 items respectively. Specific problems with each piece of 


\begin{tabular}{lll} 
Fquipment & Female Users & Cause/Reason \\
\hline 1. Safety llamess & $\begin{array}{l}\text { Improper Fit - } \\
\text { llamess to large } \\
\text { or small }\end{array}$ & $\begin{array}{l}\text { Differences in physical } \\
\text { dimensions of female } \\
\text { (height, waist, etc.) }\end{array}$
\end{tabular}

Slipping off shoulder

Energy Absorber Device

2. Scuttles and Hatches

Momentum of lighter user may not be great enough to bring absorter device into action.

Large force required to
Undesirable Result

Possible

Poorly distributed deceleration forces. Possible injuries to user in an interrupted fall.

Outward shifting of straps at shoulders - due to strap interference with bust and smaller shoulder breadth open some scuttles due to dirt \& corrosion buildup, misaligmment and other factors.

Scuttle is awkward means of passage.

Insufficient lighting.

\author{
Does not actuate \\ for lighter \\ personnel
}

Difficulty in
operating

*Falls while operating or passing through scuttle

* Fumbling to operate scuttle
User's upper torso slips Investigate problem out of harness. Poorly further. If necessary, distributed deceleration forces in an interupted fall possible injuries to user.

High deceleration forces - possible injuries to user.

Impeding of shipboard traffic - potential nazard situation.

Injuries to Personnel.

Irpeding of shipboard traffic - potential hazard situation. revise specs.

Revise specs to include a deceieration test mass as well as the further. If necessary. prescribe new specs. masntenance procecures or modifications.

Place a foothold on the way from the ladder.

Improve ligiting in passageways. modify existing hamesses, which uses a light test presently used heavy mass.

Investigate the problem opposite side of passage

Add florescent reflective arrows to indicate direction to open/close or raised arrows since scuttle is in darkness.

Potential

degradation in performance of duties possible hazard situation.

Bulk of OBA

temales is somewhat

less than for males.

Fit of CBA on ferrales may recuce ability to pass through scuttles.

Eye height/window height

Difference in height between males and females.

Addition equipment (platforms, stools) required to perform duties.

*Falling over or
between rails

Differences in body thickness, height. weight distribution Injuries to personnel. nroblems further. Determine whether adding OBA to feriale chest causes 1) movement problem - 2) too much bulk, which reduces ability to use firefighting equipment. If necessary, moduty OBA or linut users.

Utilize platforms and stools where necessary. cansider wider range of herght in future designs.

Determine whether a problem actually exists.
Investigace potontial

*Potential problems for male users also. 
equipment and recommended Navy action are summarized in Table 7 .

\subsection{REFERENCES}

1. Laubach, L. L. Muscular Strength of Women and Men: A Comparative Study. AMRL-TR-75-32, 1976.

2. Robertson, D. A. Results of Strength Tests for Development of Occupational Physical Standards. Information briefing. October 12, 1978, Bureau of Personnel, U.S. Dept. of Navy, Washington, D. C.

3. Personal Communications with LCDR James Brady, Naval Air Systems Command, U.S. Dept. of Navy, Washington, D. C.

4. Personal Communication with John Leary of Mine Safety Appliance Co.

5. AFSC Design Handbook (DH 2-8): Life Support, 2nd edition, Andrews AFB, Washington, D.C. 1978.

6. Steinberg. H. L. A Study of Personal Fall-Safety Equipment. NBSIR 76-1146 (Prepared for CSHA), June 1977.

7. Reynolds, H. M. and Allgood, M. A. Functional Strength of Commercial Airline Stewardesses. FAA-AM-75-13, November 1975 .

8. Military Standard $1472 B$, "Human Engine 6 ring Design Criteria for Military Systems Equipment and Facilities," December 31, 1974. 
Anthropometric and Biomechanical Data Capabilities

While much of the data required to assess the significance of anthropometric and biomechanical differences between male and potential female crewmembers will need to be collected, the Consumer Ergonomics and Information Group (CEIG) at NBS has a large collection of this type of data readily available as a result of the Standard Ergnomics Reference Data System (SERDS) project activity. This data collection is summarized in the References Section of this Appendix. The general applicability of each reference is further summarized for nine types of areas of measurement and whether the data is from male or female populations. It should also be noted that in addition to the data.from the sources cited in the References there are a great deal of anthropometric and biomechanical data available in miscellaneous textbooks and other sources which are either in the CEIG library or in the possession of the CEIG staff.

The data sources cited in the References Section of this Appendix and summarized in Table Al are probably representative of the published state-of-the-art in anthropometry and biomechanics in that they are most available for General Anthropometry and Push-Pull and least available for the rather ill-defined area of human torque application. The citation of only one source for Reach Envelope is not as restrictive as it appears since most general anthropometry references include simple reach data and Kennedy and Kennedy (14) is not only an up to date reference but also includes reference to and discussion of reach envelope data from other sources, e.g. Dempster, Garrett, and previous work by Kennedy. The lack of data on Position Anthropometry and Joint Movement is not too restrictive in practice since available data are basic and any other data required beyond such basic mesurements should probably be derived from a study of the performance required for a specific task. The Lift and Carry data are largely contained in Kramer and Meguire (15). This study is recent and contains an extensive data presentation from other lifting and carrying studies. Torque data are not represented for women in Table Al, although some torque data are probably available from miscellaneous sources in the CEIG literature collection. However, it should be noted that application of torque by some controls, e.g. a hand wheel, is actually push-pull 
action from the biomechanical standpoint. Hand grip strength is not shown in Table Al or cited in the References, although, again, such data are available in references in the CEIG miscellaneous collection. However relatively few tasks are performed by hand grip force alone. Although it may be critical for some types of force applications, especially for biomechanical torque through the length of the arm. there is not reference to a category such as "manual dexterity." This is because "manual dexterity" is very difficult to demonstrate as a general characteristic. Furthermore, dexterity tests, such as the Minnesota Rate of Manipulation Test, do not appear to predict performance in manual test beyond the training period, although wrist and finger dexterity may be a factor in differences in job output between two workers with long experience on a manual task.

The basic caveat to the use of data from the sources cited in the References is that anthropometric and biomechanical data are precisely valid only for the populations from which they are obtained and in terms of the methods used to obtain them. This caveat is especially applicable in the women-at-sea project since many of the factors which will influence the characteristics of the women crewmember population cannot be presently evaluated. For example, some characteristics may be influenced by whether or not sea duty is voluntary for women and, if so, on what basis. These considerations do not prohioit the use of available anthropometric and biomechanical data in defining problems associated with the utilization of women crewmembers in solving these problems. They do, however, emphasize the need for professional judginent in the selection, application, and updating of these data. A more serious restriction on the applicability of available anthropometric and biomechanical data in the women-at-sea program is that little or none of such data have beer: derived on moving platforms, such as may be a critical task performance factor in a ship at sea. This is an especially critical factor for biomechanical data. 
Summary of References* by Type

of Mcasurement and Sex Applicability

Type of Measurement

General Anthropometry

Hand Anthropometry

Head Anthropometry

Position Anthropometry

Reach Envelope

Joint Measurement

Lift and carry

Push-Pull

Torque

* Erom References, this append1x.

**Also included in most of General Anthropometry references.
Male

Female

A2, A13,A17, A 20, A 3,A 4, A5, A8, Al9, $\mathrm{A} 22, \mathrm{~A} 23$

$A 20, A 22, A 24$

A6, Al1, Al2 **

A10 *

Al **

$\star \star$

A21

A 4

A14

A14

A7

A 7

A9, Al 5

A15

A16, A21

A4, A16, A18

A12 
1. Alexander, M. ana Laubach, L.L., Anthropometry of the Human Ear. (A programmatic study of USAF flight personnel). AMRL-TR-67-203, 1968. 500 male, mean age 28.32 . 15 measurements.

A2. Body measurements for the sizing of apparel for young men (students). NBS voluntary Product standard PS 45-71. Recognized size categories, size designations, and body measurements for the sizing of apparel for young men. 26 measurements.

A3. Body measurements for the sizing of women's patterns and apparel. NBS voluntary Product standard PS 42-70, 1971. Standard classifications, size designations and body measurements for sizing of women's ready to wear apparel. 44 measurements.

A4. Churchhill, E. et al. Anthropometry of women of the U.S. Army 1977, Report No. 2 Univariate Statistics, Report No. 3 Bivariate Freguency Tables, Natick, MA. $\mathrm{TR}-77 / 024,1977,1,331+200-300$ Females, 17-60 Yrs, 142 Anthropometric and 9 Static Strength Measurements.

A5. Clauser, C.E. et al. Anthropometry of Air Force Fomen. AMRI-TR-70-5, 1972. 1905 AF Women, 18-5I years. 137 measurements including 13 with foundation garments.

A6. Clauser, C.E., Vicinus, J.H. X-ray anthropometry of the hand. ANRI-TDR-62-111, 1962253 Air Force aviators, age not specified. 44 measurements.

A7. Damon, A. et al. The human body in equipment design Harvard University Press, Cambridge, MA. 1971. Range of joint movement, male and female. Approximately 50 measurements, 1937-1957.

A 8. Daniels, G.S. et al. Anthropometry of WAF basic trainees, WADC TR 53-12, 1953. 852 female, 18-34 yrs. 63 measurements.

A9. Davis, P.R. and Stubbs, D.A. Safe levels of manual Forces for young males (I) Applied Ergonomics 2977, 8(3) pages 140-150 and (2) Applied Ergonomics $19778(4)$, pages 219-228. 12 males, under 35 years, lifting loads. Measurements in 9 positions. 
Al0. Garrett, J.W. Antiropometry of the AlP Force feinare

hand. $A M R L-T R-69-26,1970$. 211 females, 28-56

years, 56 measurements.

A11. Garrett, J.W. Anthropometry of the hands of Male Air Force flight personnel. AMRL-TR-69-42, 148 male. 20-49 years. 56 measurements of the hand.

A12. Garrett, J.W. Clearance and performance values for the bare-handed and the pressure gloved operator. AMRL-TR-68-24, 1968. 27 adult males. Hand dimensions and strength for bare-handed, gloved and gloved and pressurized suit.

A13. Gifford, E.C. et al. Anthropometry of Naval aviators 1964. NAEC-ACEL-533, 19651,549 U.S. Naval aviators, age not specified. 96 measurements.

A14. Kennedy, K.W. Reach capability of men and women: A three-dimensional analysis. AMRL-TR-77-50, 1978. 30 males and 30 females, age, mean age 20 and 26 years. 5th, 50th, 95th seated grasping reach envelopes.

A15. Kramer, J.J. and Meguire, P.G. Consumer product portability as related to warranty rule making. NBSIR 76-1092, 1976. 96 male and female, age 16-60 years. Iifting and carrying one and two handed. Also extensive survey of previous portability studies.

A16. Iaubach; I.L. Muscular strength of women and men: A Comparative Study. AMRL-TR-75-32, 1978. 31 "young". Grip, part body, whole body push pull strength for young women compared with published data for young men.

Al7. Martin: J.I. et al. Anthropometry of law enforcement officers, NELC/TD 442, 1975. 3000 males, 18.65 years, 23. measurements.

Al8. Reynolds, N.M. and Allgood, M.A. Functional strength of commercial airline stewardesses. FAA-AM-75-13, 1975. 152 female flight attendants, 13 body measurements and 4 push-pull strength tests.

A19. Snow, C.C. et al. Anthropometry of airline stewardesses FAA-AM-75-2, 1975. 423 stewardess-trainees. 72 measurements. 
120. Snyder, R.G. et al. Anthropometry of infants, children and youths to age 18 for product safety design. UM-IISRI-77-17 for CPSC, 1977. Ca. 20-40 males and females in 17.5 to 29.0 years group. 87 measurements.

121. Van Cote, H.P. and Kinkade, R.G. Human engineering guide to equipment design, Los Angeles, CA, MCGraw-Hill, 1972. Position anthropometry, males 1956 and 1965 whole body push-pull, male, six measurements, 1969.

A22. Weight, Height and selected body dimensions of adults, U.S. 1960-1962. Public Health Service, National Center for Health Statistics. Series Il, No. 8. 7,710 male and female, 18-79 years, 12 measurements.

A 23. White, R.M. et al. The body size of soldiers. U.S. Army anthropometry -1966. U.S. Army Natick Laboratories. TR 72-JI-CE, 1971. 6602 Army men. 70 measurements.

A 24. Women's Measurements for garment and pattern construeion. U.S. Department of Agriculture, Misc. Pub. No. 454, 1941. 14, 698 women. 18 years, general publication. 58 measurements.

24 


\section{APPENDIX B}

Anthroponetric and Biomechanical Dimensions of Male and Female Populations

The procedure used in the collection of the anthropowetric and bionechanical data presented in Tables 2 and 3 was 1) to select populations which were credibly similar to a reasonably expected male and female llavy crewnember population, 2) to select anthropometric and biomechanical dimensions which could economically describe the physical characteristics of these populations, and 3) to select a data format which would adequately present this description.

The populations selected were primarily Army males and fenales (Ref $B I$ and BIO) for the anthropometric dimensions and a nore diverse set of populations (Ref. B7, B9, B3, B3a, $B 3 b$, and $B 4$ ) for the biomechanical dimensions. The biomechanical populations are more diverse than the anthropometric populations for reasons of data availability.

The dimensions were selected on the basis of three criteria: 1) the sample areas which are basic to the physical description of people in a task performance situation; 2) the availability of both male and female measurements (an exception to this is Waist Front Length for females for which there was no male equivalent dimension available), and 3) they represented a mix of both general and specific measurements. The latter criterion, for example, yielded height and weight, which are highly correlated with a relatively large number of other dimensions, and bust depth, which (in wowen) is highly correlated with relatively few other dimensions. While, as noted above, none of the dimensions were specifically selected for task criticality, there was a general consideration of functional relevance to shipboard operations which served to exclude head and foot dimensions. from the brief list feasible for this report. Also, there was no attempt to select dimensions on the basis of malefemale differences as such, although, as will be seen from Table 3, such differences do energe.

The data presentation format for Table 3 lists the dimensions for which data were obtained, the population from which the data were derived, the 5th, 50th, and $95 \mathrm{th}$ 
percentiles of the data (in most cases), the relative overlap of the ranges of male and female distributions, and explanatory remarks on what the data represent.

In most cases the dimensions are identical in terminology for both men and woinen, the outstanding exception being the dimensional terminology of Bust Depth ror remales and Chest Depth for inales. This is a rather important distinction which will be discussed below.

The data presentation of 5 th, $50 t h$, and 95 th percentile (or loth percentile, inean, and 90 th percentile) shows selected points of each distribution but does not bring out the complete picture of dimensional data. This incompleteness is especially critical for arm reach dimensions. The only adequate way to evaluate arm reach dimensions for operational functions is to examine the arm reach envelope. Since such data cannot be presented in a brief form, the reader is referred to Kennedy, K.W., Reach Capability of Men and Women: A Three Dimensional Analysis. AMRL-TR-77-50, 1978, for an updated presentation of this material.

The data in Table 3 are in the generally expected direction of lower values for females than males, although this difference tends to be somewhat more pronounced for the force application dimensions than for the strictiy anthropometric dimensions. Based on average dimensional overlap values there tends to be more commonality of the male-female dimension range for "tissue-based," female dimensions, although the hand dimensions are not entirely consistent with this tendency. Sinilarity of male-female dimensions is most pronounced for Bust Depth and Chest Depth. It is probable that the female breast compensates for the smaller feinale rib cage to produce this dimensional similarity. It should be noted that the brassiere produces a chest/bust depth configuration that is not entirely anatomical. However, the female Bust Depth dimension, as shown in Table 3 , is a valid design consideration for equipment and access. 


\section{(Used $\frac{\text { REFERENCES }}{\ln \text { APPend IX B) }}$}

B1. Churchill, E. et a 1. Anthropometry of Women of the U.S. Army 1977, Report No. 2 Univariate Statistics, Report No. 3 Bivarlate Frequency Tables, Natick, MA. $T R-77 / 024,1977$.

B2. Clauser, C.E. et a1. Anthropometry of Air Force Women. AMRL-TR-70-5, 1972 .

B3. Kramer, J.J. and Meguire, P. G. Consumer Product Portability as related to warranty rulemaking. NBSIR 76-1092, 1976 .

B4. Ibid, Citing Snook, et a1., 1976.

B5. Ibid, Citing Snook and Circillo, 1974.

B6 Laubach, L.L. Muscular Strength of Women and Men: A Comparative Study. AMRL-TR-75-32, 1976.

B7. Reynolds, H. M. and Allgood, M.A. Functional Strength of Commercial Airline Stewardesses. FAA-AM-75-13, November 1975 .

B8. Robertson,. D. A. Results of Strength Tests for Development of occupational Physical standards. Information briefing, October.12, 1978, Burean of Personnel, U,S. Dept. of Navy, Washington, D, C.

B9. Snyder, R.G. et al. Anthropometry of Infants, Children and Youths to Age 18 for Product Safety Design. UM-HSRI-77-17 for CPSC, 1977.

B10. Steinberg, H.L. A Study of Personal Fall-Safety Equipment. NBSIR 76-1146 (prepared for OSHA), June 1977.

B11. Van Cott, H. P. and Kinkade, R, G. Human Engineering Guide to Equipment Design, Los Angeles, CA, McGrawHill, 1972. Citing Alexander and Clauser, 1965.

B12. White, R. M. et al. The body size of soldiers.'U.S. Army anthropometry-1966. U.S. Army Natick Laboratories. TR-72-JI-CE, 197I. 6602 Army men. 70 measurements. 

NBS-114A (REV. 9-78)

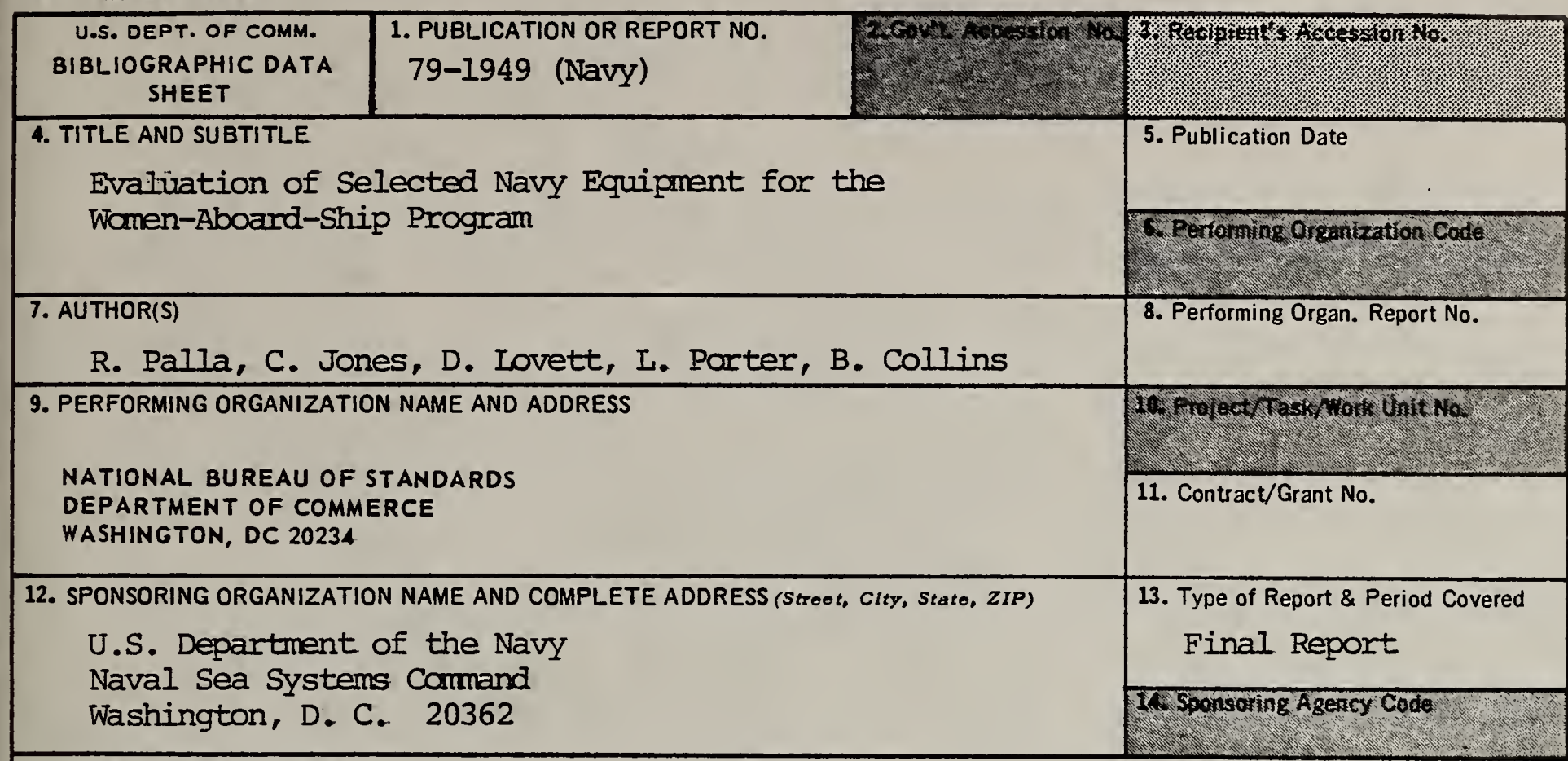

15. SUPPLEMENTARY NOTES

Document describes a computer program; SF-185, FIPS Software Summary, is attached.

16. ABSTRACT (A 200-word or loss factual summary of most significant information. If document includes a significant bibliography or literature survey, mention it here.)

A study of the human factors aspects of five selected items of Navy equipment, namely, oxygen breathing apparatus, safety harness, emergency escape scuttle, life rails, and rotary observation windows, has been undertaken to ensure that the smaller size and lesser strength of females would not be a deterrent to the use of the equipment by women. The study involved a review of the applicable specifications for each item of equipment, a survey and emmeration of male and female anthropometric data, and a linking of engineering and anthropometric data. Each item has been assigned to a hazard category.

Of the five items evaluated, two appear to pose significant problems when used by women. Fit and high deceleration forces were the major concerns for the safety harness while operating force requirements were critical for the escape scuttle. In addition, there were also some difficulties for some women in the use of the oxygen breathing apparatus.

17. KEY WORDS (six to twelve entries; alphabetical order; capitalize only the first letter of the first key word unless a proper name; soparatod by semicolons)

Anthropometry, equipment evaluation, escape scuttles, female, oxygen breathing apparatus, performance, safety evaluation, safety harness, safety hazards.

18. AVAILABILITY

For Official Distribution. Do Not Release to NTIS

Order From Sup. of Doc., U.S. Government Printing Office, Washingtion, DC 20402, SD Stock No. SNÓ03-003-

Order From National Technical Information Service (NTIS), Springfield, VA. 22161

\begin{tabular}{|l|l|}
\hline $\begin{array}{l}\text { 19. SECURITY CLASS } \\
\text { (THIS REPORT) }\end{array}$ & $\begin{array}{l}\text { 21. NO. OF } \\
\text { PRINTED PAGES } \\
\text { UNCLASSIFIED }\end{array}$ \\
\hline $\begin{array}{l}\text { 20. SECLRITY CLASS } \\
\text { (THIS PAGE) } \\
\text { UNCLASSIFIED }\end{array}$ & 22. Price \\
\hline
\end{tabular}


